\title{
Self-emulsifying Delivery System in Solubility and Dissolution Enhancement of Cardiovascular Drug Akiladevi $D^{* 1}$, Nappinnai $M^{2}$, Jerad Suresh $A^{3}$, Amudha $P^{4}$, Vetrichelvan $T^{5}$
}

\begin{abstract}
${ }^{1}$ Department of Pharmaceutics, Adhiparasakthi College of Pharmacy, Melmaruvathur-603319, Tamilnadu, India
${ }^{2}$ Department of Pharmaceutics, Surya Group of Institutions, School of Pharmacy, Vikravandi, Villupuram-605 652, Tamilnadu, India

${ }^{3}$ Department of Pharmaceutical Chemistry, College of Pharmacy, Madras Medical College, Chennai-600 003, Tamilnadu, India

${ }^{4}$ Department of Pharmacology, CL Baid Mehtha College of Pharmacy, Thorapakkam, Chennai, Tamilnadu, India

${ }^{5}$ Department of Pharmaceutical Analysis, Adhiparasakthi College of Pharmacy, Melmaruvathur-603 319, Tamilnadu, India
\end{abstract}

*Corresponding author: Akiladevi D, Department of Pharmaceutics, Adhiparasakthi College of Pharmacy, Melmaruvathur-603319, Tamilnadu, India, E-mail: akilaajcp@gmail.com

Received: February 26, 2017; Revised: March 01, 2017; Published: March 12, 2017

Copyright: @2017 Akiladevi D, et al. This is an open-access article distributed under the terms of the Creative Commons Attribution License, which permits unrestricted use, distribution, and reproduction in any medium, provided the original author and source are credited. The article has been previewed and authenticated by the Authors before sending the publication for print. The Journal, Editor and the Editorial Board are not entitled or liable to either justify or responsible for inaccurate and misleading data if any. It is the sole responsibility of the Author concerned.

Citation: Akiladevi D, Nappinnai M, Jerad Suresh A, et al. Self-emulsifying Delivery System in Solubility and Dissolution Enhancement of Cardiovascular Drug. Int J Pharm Pharmacol 2017; 1: 102.

\begin{abstract}
Objective: The objective of the present study was to formulate and develop a self-emulsifying drug delivery system for poorly water soluble cardiovascular drug of atorvastatin calcium (atc) (SEDDS) by improving its solubility and dissolution characteristics, thereby enhancing its relative bioavailability.

Methods: Atorvastatin calcium was identified by Fourier transform infrared (FT-IR) spectroscopic study. The SEDDS was prepared using sunflower oil, labrasol and transcutol HP as an oil phase, surfactant, and co-surfactant respectively. Initially, the solubility of atc was examined in different oils, surfactants and co-surfactants, and ternary phase diagrams were constructed subsequently to optimize the ratio of the excipients having greater microemulsion region. The self-emulsifying batches of atc were developed with the optimized excipients and evaluated for droplet size, polydispersity index, drug loading, zeta potential, optical clarity, turbidity, cloud point, viscosity determination, selfemulsification time assessment and in vitro drug release.

Results: The in vitro dissolution studies revealed that the optimized formulation of atorvastatin calcium showed more than $90 \%$ of drug release within 30 minutes when compared to that of marketed tablet.

Keywords: Cardiovascular drug, In vitro drug release, Solubility, Ternary phase diagram, Selfemulsifying system
\end{abstract}

Introduction

Akiladevi D, et al. Int J Pharm Pharmacol
Oral drug bioavailability of a chemically stable drug is limited by its solubility and its 
permeability. The poor drug absorption, therefore, can be caused by inadequate rate and extent of drug dissolution and or low permeation. As per the biopharmaceutical system of classification, a drug is classified into four possible categories, class I to IV on the basis of these solubility and permeability characteristics. The bioavailability of poorly soluble class II drugs, on the contrary, is dependent on their aqueous solubility and dissolution rate [1]. As these drugs tend to exhibit dissolution limited bioavailability, the in vivo physiological response is well correlated with the in vitro dissolution, resulting eventually in good in vitro/in vivo correlations.

Self-Emulsifying Drug Delivery Systems (SEDDS) are promising approaches for enhancing bioavailability of low soluble drugs of biopharmaceutical classification. The main benefit of this approach is that dissolving the compound by overcoming the initial ratelimiting step of dissolution in the aqueous environment within the gastrointestinal tract [2]. SEDDS are isotropic mixtures of oils and surfactants, sometimes containing co-solvents, and it can be used for the design of formulations in order to improve the oral absorption of highly lipophilic compounds. Their dispersion in gastro intestinal (GI) fluid after administration forms micro or nanoemulsified drug which gets easily absorbed through lymphatic pathways by passing the hepatic first pass metabolism. These systems have the advantage that the drug in dissolved form and the small droplet size provides a large interfacial area for the drug absorption [3]. SEDDS typically produce emulsions with a droplet size between few nanometers (100-300 $\mathrm{nm})$ to several microns $(<5 \mu \mathrm{m})$ while selfmicro-emulsifying drug delivery systems (SMEDDSs) form transparent micro-emulsions with a droplet size of less than $50 \mathrm{~nm}$. SEDDS are physically stable formulations that are easy to manufacture, but when compared with emulsions, which are metastable dispersed forms. Thus, for lipophilic drug compounds that exhibit dissolution rate-limited absorption, these systems may offer an improvement in the rate and extent of absorption and result in more reproducible blood-time profiles [4]. The potential drug candidates for the formulation of SEDDS are BCS class II and class IV drugs.
Atorvastatin calcium a 3-hydroxy-3methylglutaryl coenzyme A (HMG-CoA) reductase inhibitor is a plasma lipid regulating agent. The oral bioavailability of atorvastatin calcium is only $14 \%$ and poor bioavailability has been attributed to its poor solubility in water and high presystemic clearance $(>80 \%)$. Atorvastatin calcium a BCS class II drug of log $\mathrm{p}$ (octanol /water) of 5.39 was selected for the formulation of SEDDS owing due to poor water solubility and poor permeability.

In the present research work for development of SEDDS it was planned to use a variety of modified long chain triglycerides natural oils (corn oil, olive oil, sesame oil, sunflower oil) long chain monoglycerides (Peceol) and medium chain triglycerides (coconut oil) with varying degree of saturation of hydrolysis because these oils offer distinct formulation and physiological advantages as their degradation products resemble that of natural end products of intestinal digestion [5]. The long chain triglyceride offers many other advantages such as easy availability in large quantities from a natural source, toxicologically safe, completely biocompatible and costeffective replacement for commercial triglycerides and modified oils. In a comparative research study of Cornaire $\mathrm{G}$ et al. in the evaluation of P-gp inhibition of ten excipients labrasol was identified as the most effective excipient [6] and it improved the transcellular transport of BCS class II drugs through intestinal cell membranes. The excipients containing some esters of unsaturated fatty acid proved the enhancement of bioavailability of a poorly water soluble drug of ontazolast with peceol [7] through the lymphatic transport system. The newer cosurfactant transcutol HP was utilized in this research work for its better stability and less volatility.

Initially, solubility studies of atc in different excipients were performed, and ternary phase diagrams were constructed to obtain optimum emulsification region. The SEDDS were formulated with the optimized ratios of excipients and evaluated for droplet size, drug loading, zeta potential, polydispersity index optical clarity, turbidity, cloud point, viscosity determination, self-emulsification time assessment and in vitro drug release in and phosphate buffer ( $\mathrm{pH}$ 6.8). 


\section{Materials and Methods}

\section{Materials}

Atorvastatin calcium was generously gifted by Goodman Pharmaceuticals, Pondicherry. Capryol PGMC transcutol HP, peceol, labrasol, labrafil M 1944 CS and labrafil M 2125 CS were gift samples from Gattefosse, Mumbai. Virgin sesame oil, virgin coconut oil and sunflower oil from Vama oil industries, Coimbatore, Olive oil from Shaah Enterprises, Chennai, Mustard oil from Green spice products, Coimbatore, Rice bran oil from Jupiter Manufacturing industry, Chennai, Corn oil from Arumuga group of industries, Tamilnadu were purchased for the research work. All other chemicals were of analytical grade.

\section{Fourier Transform Infrared (FT-IR) Spectroscopy of Atorvastatin Calcium}

The drug sample was mixed with anhydrous potassium bromide $(\mathrm{KBr})$ in 1:4 ratios. Briefly about $100 \mathrm{mg}$ of this mixture was made into fine powder using mortar and pestle followed by compression to form transparent $\mathrm{KBr}$ pellet using Techno search hydraulic press set at 15-ton pressure. Each $\mathrm{KBr}$ pellet was scanned at $4 \mathrm{~mm} / \mathrm{s}$ at a resolution of $2 \mathrm{~cm}$ over a wave number region from 4000 to $400 \mathrm{~cm}^{-1}$ in an FTIR spectrophotometer (8400S Shimadzu, Japan).

\section{Solubility Studies}

The solubility for atorvastatin calcium were determined in aqueous solutions of various $\mathrm{pH}(\mathrm{pH} 4$ and 7.4), distilled water, organic solvents such as dimethylsulphoxide and dimethylformamide. Aqueous solution of $\mathrm{pH} 4.0$ and 7.4 was obtained by adding suitable amount of dilute hydrochloric acid and dilute sodium hydroxide. About $2 \mathrm{ml}$ of each solvent was transferred into $5 \mathrm{ml}$ glass vial and an excess quantity of drug (150 mg) was added to the vial. The solubility of the drug samples was also analyzed by adding excess amount (150 $\mathrm{mg}$ ) of the drug to $2 \mathrm{ml}$ of various oils, surfactants, and co-surfactants in screw capped glass vials followed by vortex mixing for 30 sec using vortex mixer (Sphinx, Japan). The mixtures were shaken for $48 \mathrm{~h}$ at $30^{\circ} \mathrm{C}$ in a thermostatically controlled shaking water bath, Akiladevi D, et al. Int J Pharm Pharmacol followed by equilibrium for $24 \mathrm{hr}$. The sample mixtures were then centrifuged at $3000 \mathrm{rpm}$ [8] for $10 \mathrm{~min}$ and the supernatant liquid was filtered through a millipore membrane filter $(0.45 \mu)$. Samples were suitably diluted with methanol followed by sonication for $10 \mathrm{~min}$ and finally diluted with the same solvent. The final drug concentration was quantified by UVvisible spectrophotometer at $247 \mathrm{~nm}$ for atorvastatin calcium. The experiment was repeated in triplicates. The results are represented as mean value $(\mathrm{mg} / \mathrm{ml}) \pm \mathrm{SD}$.

\section{Construction of Ternary Phase Diagram}

Based on the results of saturation solubility studies in Table 1, sunflower oil, labrasol and transcutol HP for atorvastatin calcium were selected as oil, surfactant and cosurfactant respectively. A ternary phase diagram was constructed for the system containing oil-surfactant-co-surfactant by Chemix School software version 3.51. The grading method reported by Craig et al. [9] was modified and adopted in this study. A series of self-emulsifying systems were prepared with varying weight percentage of oil, surfactant, and co-surfactant. Since the drug incorporated in the SEDDS may have some effect on selfemulsion boundary, every system in the series also consisted of $10 \% \mathrm{w} / \mathrm{w}$ for atorvastatin calcium. The extreme and middle level of the independent variables consisting of oil, surfactant and co-surfactant were selected for further study. $0.2 \mathrm{ml}$ of each formulation was introduced into $200 \mathrm{ml}$ of water in a glass beaker maintained at $37^{\circ} \mathrm{C}$ and was mixed gently about $200 \mathrm{rpm}$ with a magnetic stir bar. The tendency to emulsify spontaneously and the progress of emulsion droplets spread were observed. The tendency to form an emulsion was judged as 'good' when droplets spread easily in water and formed a fine milky or slightly bluish emulsion within $1 \mathrm{~min}$. It was judged 'bad' when there was poor, slow or no emulsion formation or when oil droplets coalesce when stirring was stopped or when dull, grayish white emulsion was formed. All studies were repeated thrice.

\section{Preparation of SEDDS}

Optimum ratios of oil and Smix (surfactant and cosurfactant mixture) were 
selected from the phase diagrams. SEDDS formulations were prepared by dissolving the drug in Smix mixtures along with gentle vortexing and sonicating and then by adding oil [10]. Nine different batches were prepared with each batch of SEDDS formulation containing single dose of atorvastatin with varying amounts of oil and Smix of nine formulations as illustrated in Table 2. Then the final formulation was equilibrated in water bath at $37^{\circ} \mathrm{C}$ for $48 \mathrm{~h}$ before carrying out the droplet size, polydispersity index and dissolution.

\section{Self-emulsification and Drug Precipitation Studies}

The efficiency of self-emulsification of oral micro/nano-emulsion is assessed by dispersibility test using a standard USP dissolution apparatus II [11]. One $\mathrm{ml}$ of each formulation is added to $500 \mathrm{ml}$ of water at $37 \pm$ $0.5^{\circ} \mathrm{C}$. A standard stainless steel dissolution paddle rotating at $50 \mathrm{rpm}$ tends to provide gentle agitation. The in vitro performance of the formulations is visually assessed from such dispersion, using a suitable grading system after $24 \mathrm{~h}$. The in vitro performance of the formulations is visually assessed using the following grading system:

Grade I: Rapidly forming (within $1 \mathrm{~min}$ ) nano emulsion, having a clear or bluish appearance. (Micro emulsion)

Grade II: Rapidly forming, slightly less clear emulsion, having a bluish white appearance. (Micro emulsion gel)

Grade III: Fine milky emulsion that formed within 2 min. (Emulsion)

Grade IV: A dull greyish white emulsion having slightly oily appearance that is slow to emulsify is formed (longer than $2 \mathrm{~min}$ ). (Emulgel)

Grade V: Formulation, exhibiting either poor or minimal emulsification with large oil globules present on the surface with phase separation is observed.

Grade VI: The drug is precipitated.

Grade I and Grade II formulation will remain as nano-emulsion when dispersed in GIT. The formulation falling in Grade III is recommended for SEDDS formulation. The primary means of self-emulsification is a visual evaluation. The efficiency of selfemulsification could be estimated by determining the rate of emulsification, droplet size distribution, and turbidity measurements.

\section{Phase Separation Study}

The self-emulsifying formulation was diluted with distilled water up to 5 times and the temperature was maintained at $25^{\circ} \mathrm{C}$. The mixture was then mixed for $2 \mathrm{~min}$, stored for about $2 \mathrm{~h}$ and visually observed for any phase separation.

\section{Determination of Emulsification Time}

The emulsification time (the time for a preconcentrate to form a homogeneous mixture upon dilution) was monitored by visually observing the disappearance of SEDDS and the final appearance of the emulsion in triplicate. A dissolution apparatus USP II (Electrolab) was employed with $500 \mathrm{ml}$ water and with a paddle speed of $50 \mathrm{rpm}$ at $37^{\circ} \mathrm{C}$. The SEDDS $(1 \mathrm{ml})$ was added drop wise to the medium by dropping the pipette and time required for the disappearance of SEDDS was recorded.

\section{Spectroscopic Characterization of Optical Clarity}

SEDDS formulations disperse in aqueous phase forming the emulsion or micro emulsions and can be detected by the final appearance and droplet size. In practice, the key difference between the emulsion and micro emulsions concerns with their appearance. Emulsions are cloudy while micro emulsions are clear or translucent and the reason for their transparency appearance is due to very small droplet size. The optical clarity may be checked visually. But in order to measure it quantitatively, a UV-visible spectrophotometer was used to measure the amount of light of a given wavelength absorbed by the solution. The cloudier solutions will absorb more of the incident light, resulting in higher absorbance values and lower absorbance is obtained with optically clear solutions.

The optical clarity of aqueous dispersions of SEDDS formulations was measured spectroscopically. About $1 \mathrm{ml}$ of SEDDS formulations were diluted to 50 times with double distilled water. The absorbance values of each formulation were measured by a UV-visible spectrophotometer (Shimadzu) at $400 \mathrm{~nm}[12]$. 


\section{Turbidity Measurement}

The measurement of turbidity is to analyse whether the dispersion reaches equilibrium rapidly and in a reproducible time. The growth of emulsification is done by nepheloturbidimetric evaluation. The turbidity measurements in nephelometric turbidity unit (NTU) were performed on the resultant emulsion stored in a screw capped sample vials using a turbid meter (Elico D-10-model 331). $0.5 \mathrm{ml}$ of the SEDDS formulation was introduced into $250 \mathrm{ml}$ of distilled water in 500 $\mathrm{ml}$ conical flask under an action of magnetic stirrer rotating at constant speed. The emulsification was done at room temperature [13].

\section{Viscosity Determination}

The viscosity studies are necessary for SEDDS to characterize the system physically and to control its stability. If the system has low viscosity then, it is o/w type of the system and if a high viscosity then it is w/o type of the system. SEDDS preconcentrate $(10 \mathrm{ml})$ was taken and its viscosity was measured by using Brookfield viscometer (Brookfield engineering Laboratories, USA) using spindle C 16-1 at 25 $\pm 0.5^{\circ} \mathrm{C}$ with a shear rate of $50 \mathrm{rpm}$.

\section{Cloud Point Measurement}

Cloud point temperatures (Tc) was determined by visual observation. $0.5 \mathrm{ml}$ of preconcentrate was diluted to $50 \mathrm{ml}$ with distilling water in a glass beaker. The sample was heated at the rate of about $0.5^{\circ} \mathrm{C} / \mathrm{min}$. A close observation was made at the appearance of the dispersion with the increase in temperature. The temperature at which the dispersion became turbid was taken as Tc. After the temperature exceeds the cloud point, the sample was cooled below Tc, and then it was heated again to check the reproducibility of the measurements. It mainly insists about the stability of micro emulsion at body temperature.

\section{Determination of Refractive Index}

The refractive index, $\mathrm{n}$, of a medium is defined as the ratio of the speed, c, of a wave such as light or sound in a reference medium to Akiladevi D, et al. Int J Pharm Pharmacol the phase speed, vp, of the wave in the medium represented by $n=c / v p$. It was determined using an Abbes type refractometer. The clarity of micro emulsion could be estimated by measuring the refractive index of the formulations. The SEDDS formulations were diluted 100 times with water. The refractive index of the system was measured by an Abbe refractometer by placing 1 drop of solution on the slide and it compares with distilled water.

\section{Droplet Size and Polydispersity Index (PDI) Analysis}

The droplet size of the micro/nano emulsions is determined by photon correlation spectroscopy (which analyses the fluctuations in light scattering due to a Brownian motion of the particles) using a Zetasizer which can measure sizes between 10 and $5000 \mathrm{~nm}$. PDI is a measure of particle homogeneity and it varies from 0.0 to 1.0. The closer to zero the PDI value the more homogenous are the particles. The mean droplet size and polydispersity index of formulations were determined by using Malvern Nano Zeta sizer-90. The resultant SEDDS $0.5 \mathrm{ml}$, was diluted to $100 \mathrm{ml}$ with double distilled water. The samples were loaded into a cuvette placed in a thermostatic chamber and light scattering was monitored at $25^{\circ} \mathrm{C}$ at a $90^{\circ}$ angle [14] after external standardization with spherical polystyrene beads.

Each determination was done in triplicate. The nanometric size range of the particle is retained even after 100 times dilution with water which proves the systems compatibility with excess water.

\section{Zeta Potential Measurement}

The zeta potential of prepared SEDDS formulations was determined using a Zeta sizer ZS 90 (Malvern Instruments UK) by using laser Doppler micro-electrophoresis. A suitable amount of the sample $(50-100 \mu \mathrm{l})$ was diluted with $5 \mathrm{ml}$ of distilled water and after sonicating in a bath sonicator to achieve a homogeneous state. Measurements were carried out at $25^{\circ} \mathrm{C}$ using disposable polystyrene cuvette with a zeta dip cell. All the measurements were performed in triplicate and the data presented is mean \pm SD. 


\section{Drug Loading Efficiency [15]}

The drug efficiency was done to investigate the effect of drugs on a selfemulsifying performance of SEDDS. Approximately $10 \mathrm{mg}$ of atorvastatin calcium was added to $1 \mathrm{ml}$ of boundary formulations of SEDDS and checked for a formation of the clear solution.

\section{Prototype Formulation for Atorvastatin Calcium}

Prototype formulations of atorvastatin calcium were prepared by varying sunflower oil in 3:1 ratios of the mixture of labrasol and transcutol HP as per the formula composition mentioned in Table 2. In the first trial, the oil was used at $40 \%$ and increased up to $80 \%$. The ratio of surfactant to co-surfactant was maintained at $3: 1$. Then drug of one dose equivalent of $10 \mathrm{mg}$ atorvastatin calcium was added and stirred for $15 \mathrm{~min}$. The mixture was heated to $30-40^{\circ} \mathrm{C}$ till the drug was solubilized. The drug loading capacity of each mixture was determined by adding the excess of atorvastatin calcium to each prototype mixture till the clear solution was obtained. The solution was filtered.

The drug content of the SEDDS formulation was determined by diluting the solution in methanol and the volume was made up to $10 \mathrm{ml}$ with methanol $(1 \mathrm{mg} / \mathrm{ml})$. From the above stock solution, $0.2 \mathrm{ml}(200 \mu \mathrm{g} / \mathrm{ml})$ was withdrawn and diluted up to $10 \mathrm{ml}$ with methanol $(20 \mu \mathrm{g} / \mathrm{ml})$. From the above solution $0.2 \mathrm{ml}(20 \mu \mathrm{g} / \mathrm{ml})$ diluted up to $10 \mathrm{ml}$ with methanol $(2 \mu \mathrm{g} / \mathrm{ml})$ Samples were prepared in triplicate and absorbance was measured at 247 $\mathrm{nm}$ using UV-visible Spectrophotometer (Shimadzu UV-1700) using methanol as a reference solution.

Drug loading efficiency was calculated by equation:

Drug loading efficiency $=$ Amount of drug in known amount of formulation X 100 / Initial drug load

\section{In Vitro Dissolution Studies for Atorvastatin Calcium}

The in vitro studies were performed to find out the dissolution rate of SEDDS. The in vitro drug release [16] profiles of optimized atorvastatin of SEDDS, API atorvastatin calcium and marketed atorvastatin calcium tablet (Storvas $10 \mathrm{mg}$ Ranbaxy Laboratories Ltd) were carried out using USP type II dissolution test apparatus (Electrolab) in 900 $\mathrm{ml}$ of Phosphate buffer ( $\mathrm{pH}$ 6.8). The temperature was maintained at $37 \pm 0.5^{\circ} \mathrm{C}$ and the speed of the paddle was set at $100 \mathrm{rpm}$. About $120 \mathrm{mg}$ of each optimized SEDDS formulation (AF4) were filled into soft gelatin capsules (size ' 3 ') and used for dissolution studies. The capsules were held to the bottom of the vessel using copper sinkers. At predetermined time intervals of $5,10,20,30$, 40, 50, 60, 75 and $90 \mathrm{~min}$, an aliquot $(5 \mathrm{ml})$ of a sample were collected and filtered through the membrane filter $(0.45 \mu \mathrm{m}$, Whatman $)$. The withdrawn samples were diluted suitably with phosphate buffer ( $\mathrm{pH}$ 6.8) and analyzed for the drug content by standard calibration curve method by UV-visible spectrophotometer (Shimadzu UV-1700) at $247 \mathrm{~nm}$. An equal volume of the dissolution medium was replaced in the vessel after each withdrawal to maintain the sink condition. The dissolution profile of the atorvastatin calcium (API) and marketed tablet (Storvas $10 \mathrm{mg}$ ) were assessed by the same method.

\section{Discussion}

\section{FT-IR Studies for Atorvastatin Calcium}

From Figure 1 it was illustrated that the IR spectrum of atorvastatin calcium showed the characteristic peaks of aromatic N-H stretching at $3364.93 \mathrm{~cm}^{-1}$ and the asymmetric stretching of $\mathrm{C}=\mathrm{O}$ of amide group at $1651.12 \mathrm{~cm}^{1}$. However, similar peaks of symmetric $\mathrm{C}=\mathrm{O}$ stretching were observed at $1579.75 \mathrm{~cm}^{-1}$ and $\mathrm{O}-\mathrm{H}$ stretching at $3566.50 \mathrm{~cm}^{-1}$. The characteristic peaks were observed at the wave numbers $1510.31 \mathrm{~cm}^{-1}$ and $1424.48 \mathrm{~cm}^{-1}$ due to the $\mathrm{C}=\mathrm{C}$ ring stretching. The peak found at $1317.43 \mathrm{~cm}^{-1}$ was due to $\mathrm{CH}_{3} / \mathrm{CH}_{3}$ deformation bending vibration at the plane. The two characteristic bands were observed at 3735.28 $\mathrm{cm}^{-1}$ and $3055.35 \mathrm{~cm}^{-1}$ due the $\mathrm{O}-\mathrm{H}$ stretching associated with the hydrogen bond. From the above study, it was inferred that the drug sample was identified as atorvastatin calcium.

\section{Solubility Study}


The atorvastatin calcium was found to have maximum solubilizing capacity in sunflower oil which is a long chain triglyceride, capable of solubilizing the drug in a specific amount facilitate self-emulsification and increase the fraction of atorvastatin calcium through the intestinal lymphatic system. The labrasol which showed the highest solubilization capacity was selected as surfactant followed by capryol PGMC, labrafil 1944 CS, Labrafil 2125 for formulation of atorvastatin calcium SEDDS as shown in Table 1. Transcutol HP showed maximum solubility for atorvastatin calcium and it was selected as the cosurfactant for the formulation of SEDDS.

\section{Construction of Phase Diagram}

As observed from the ternary plot in Figure 2 sunflower oil gave a wider micro emulsion region at 3:1 Smix ratio for atorvastatin calcium. However, it was observed that increasing the surfactant ratio resulted in a loss of flowability and increase in surfactant toxicity. The percentage of oil, surfactant and cosurfactant selected for both the drugs were selected from the phase diagram and only those formulations which used the minimum and maximum concentration of Smix were taken for the formulation of SEDDS. Based on the feasibility of micro emulsion formation at extreme values, the range for each component was selected as follows: oil (40-80\%), Smix (30-70\%) for atorvastatin calcium.

\section{Self-emulsification, Drug Precipitation, Phase Separation and Assessment of Emulsification Time Studies}

The self-emulsification was visually assessed to measure the apparent spontaneity of nano-emulsion formation. SEDDS when diluted in water were found to be non-turbid and bluish transparent in appearance indicating spontaneous emulsification. All the resulting nanoemulsions were transparent with some opalescence in appearance and did not show any sign of phase separation. In the study formulations AF4 does not show any signs drug/excipient precipitation or phase separation were found and the results are shown in Table 3.

All the results of the nano-emulsion formulations were transparent and their absorbance's were below 1 which showed good optical clarity as illustrated in Table 4. The selection of surfactants and cosurfactants are determined by emulsification ability which depends on the physicochemical properties such as globule size, Zeta potential, turbidity measurement and PDI of the resulting nanoemulsion. All the formulations of atorvastatin calcium showed rapid emulsification time within a minute as indicated in Table 4 which proves the performance of the formulations for enhancing the dissolution profile. Thus, it can be concluded that the absorption of the drug can be increased in vivo if the formulations have low emulsification time. The results are correlated with the findings of Warisnoicharoen et al. [17] which concluded that emulsification is also influenced by the structure and chain length of the surfactant. Labrasol a hydrophilic surfactant having HLB value of 12 rendered very good nanoemulsions that required a short emulsification period.

\section{Turbidity Measurements}

The turbidity of SEDDS was performed determined as per procedure and turbidity of AF4 was found to below 100NTU which shows the stability of SEDDS and the results were shown in Table 4.

In the formulation AF3 of atorvastatin calcium the turbidity value was high of 210 NTU due to the larger droplet size of the emulsion formed of $290 \mathrm{~nm}$ which was shown in Table 4.

\section{Refractive Index and Viscosity Measurement}

There was no significant difference in the refractive index values of the formulations tested. The refractive index values close to that of the water (1.333) prove the isotropicity of the formulations as indicated in Table 4.

\section{Droplet Size}

The globule size observed for all the formulation was less than $500 \mathrm{~nm}$ which were shown in Table 2. The drug loading did not show significant difference in the polydispersity values. The droplet size distribution is one of the most important characteristics of nano-emulsion for stability 
evaluation and is a critical step in the pathway of enhancing drug bioavailability. The smaller nano-emulsion particle size leads to larger interfacial surface area, thus promoting rapid absorption and improved bioavailability.

\section{Zeta Potential}

The zeta potential of the optimized formulation of AF4 of atorvastatin calcium was found to be $-31.8 \mathrm{mV}$ which were nearer the limits with good separation. The zeta potential value was found to carry negative charges due to the presence of free fatty acids. Significant increase in the value of zeta potential was observed after drug loading, higher absolute values of zeta potential generally, indicated an increase of electrostatic repulsive forces between emulsion droplets preventing the coalescence droplets and increases in the stability. Among all the vehicles tested Labrasol (surfactant) and Transcutol HP (cosurfactant) proved to be the most promising vehicles for SEDDS formulation.

\section{Polydispersity Index}

The PDI for all the formulations were less than 0.5 , formulation with combination of Smix showed lower PDI values as illustrated with the results given in Table 4 thus indicating the uniform size distribution improving the performance of the spontaneous emulsification.

\section{Cloud Point}

The cloud point is an essential factor in the SEDDS consisting of non-ionic surfactants, and it is responsible for the successful formation of a stable microemulsion. When the temperature is higher than the cloud point, an irreversible phase separation will occur and the cloudiness of the preparation would have a bad effect on drug absorption, because of the dehydration of the polyethylene oxide moiety. Hence, the cloud point for SMEDDS should be above $37^{\circ} \mathrm{C}$, which will avoid phase separation occurring in the gastrointestinal tract. The cloud point for all the formulation as shown in Table 4 tested was above $37^{\circ} \mathrm{C}$. Therefore, it would suggest a stable micro emulsion can be formed at physiological temperature in-vivo.

\section{Drug Loading}

The drug loading was calculated from the standard calibration curve of atorvastatin calcium in methanol using the linear regression equation $y=0.045 x+0.003$ with the correlation co efficient $\left(\mathrm{r}^{2}\right)$ of 0.999 . The maximum drug loading for atorvastatin calcium SEDDS has been obtained ranging from $7.1 \mathrm{mg}$ to $9.15 \mathrm{mg}$. The maximum drug loading of $8.72 \mathrm{mg}$ for atorvastatin calcium can be incorporated safely in to the optimized formulation of AF4.

\section{In Vitro Dissolution Study}

The drug concentration was calculated from the linear regression equation for atorvastatin calcium in phosphate buffer $\mathrm{pH} 6.8$ is $y=0.012 x+0.001$ with the correlation co efficient of 0.999 . The dissolution study for atorvastatin calcium API, marketed formulation and optimized formulation of AF4 were performed in $6.8 \mathrm{pH}$ phosphate buffer. The comparison results in Figure 3 and Table 5 depicted that the optimized formulation AF4 showed more than $90 \%$ drug release in $30 \mathrm{~min}$ of atorvastatin from SEDDS formulations. The rapid release of atorvastatin from SMEDDS formulations could be attributed to the spontaneous formation of micro emulsion with a small droplet size, which permitted a faster rate of drug release into the aqueous phase, much faster than that of plain atorvastatin. Thus, this greater availability of dissolved atorvastatin from the SEDDS formulation could lead to higher absorption and higher oral bioavailability.

\section{Conclusion}

The optimal atorvastatin calcium SEDDS containing sunflower oil as oil phase, labrasol as a surfactant and transcutol HP as cosurfactant (Smix) formulates SEDDS with lower droplet size $(169.7 \mathrm{~nm})$ and percentage drug load $(87.2 \%)$ values. The in vitro drug release from optimized atorvastatin SEDDS formulation were found to be $99.75 \%$ after 90 min was higher in comparison to the marketed formulation and API suspension. It could be concluded that increase in solubility profile of atorvastatin calcium by formulating through SEDDS as a potential carrier could be employed successfully as an alternative approach for improved dissolution profile for atorvastatin calcium. 


\section{Conflict of Interest} interest.

The authors declare no conflict of

\section{References}

1. Jaiswal P, Aggarwal G, Harikumar SL, et al. Bioavailability enhancement of poorly soluble drugs by SMEDDS: a review. J Drug Deliv Therap 2013; 3: 98-109.

2. Shah NH, Carvagal MT, Patel CL, et al. Self-emulsifying drug delivery systems with polyglycolyzed glycerides for improving in vitro dissolution and oral absorption of lipophilic drugs. Int $\mathbf{J}$ Pharm 1994; 106: 15-23.

3. Gursoy RN, Benita S. Self-emulsifying drug delivery systems for improved oral delivery of lipophilic drugs. Biomed Pharmacother 2004; 58: 173-182.

4. Singh SK, Priya Ranjan Prasad Verma PRP, Razdan B. Glibenclamide-loaded self-nano-emulsifying drug delivery system: development and characterization. Drug Dev Ind Pharm 2010; 36: 933-945

5. Chen ML. Lipid excipients and delivery systems for pharmaceutical development: A regulatory prospective. Adv Drug Deliv Rev 2008; 60:768-77.

6. Cornaire G, Houin G, Arellano C, et al. Impact of excipients on the absorption of P-glycoprotein substrates in vitro and in vivo. Int J Pharm 2004; 278: 119131.

7. Hauss DJ, Fogal SE, Ficorilli JV. LipidBased Delivery Systems for Improving the Bioavailability and Lymphatic Transport of a Poorly Water-Soluble LTB $_{4}$ Inhibitor. J Pharm Sci 1998; 87:164-169.

8. Bora DK, Borude P, Bhise K. Formulation and Evaluation of Self microemulsifying drug delivery system of low solubility drug for enhanced solubility and dissolution. Asian J Biomed Pharmaceut Sci 2012; 15: 7-14.

9. Craig DQM, Barker SA, Banning D, et al. An investigation into mechanism of self-emulsification using particle size analysis and low frequency dielectric spectroscopy. Int J Pharm 1995; 114: 103-110.

10. Chouksey R, Pandey H, Jain AK, et al. Preparation and evaluation of the selfemulsifying drug delivery system containing atorvastatin HMG-CoA inhibiter. Int J Pharm Pharm Sci 2011; 3: 147-152.

11. Shafiq S, Shakeel F, Talegaonkar S, et al. Development and bioavailability assessment of ramipril nanoemulsion formulation. Eur J Pharm Biopharm 2007; 66: 227-243.

12. Subramanian N, Ray S, Ghosal SK, et al. Formulation Design of SelfMicroemulsifying Drug Delivery Systems for Improved Oral Bioavailability of Celecoxib. Biol Pharm Bull 2004; 27: 1993-1999.

13. Balakrishnan P, Lee BJ, Oh DH, et al. Enhanced oral bioavailability of coenzyme Q10 by a novel solid selfemulsifying drug delivery system. Int $\mathbf{J}$ Pharm 2009; 374: 66-72.

14. Kim JY, Young SK. Enhanced absorption of Indomethacin after oral or rectal administration of Self emulsifying system containing Indomethacin torats. Int J Pharm 2000; 194: 81- 89.

15. Puttachari S, Kalyanea NV, Gupta SD. Design and evaluation of self-micro emulsifying drug delivery systems of acyclovir. Int J Pharm Pharm Sci 2014; 6: 677-681.

16. Belhadj Z, Zhang S, Zhang W, et al. Formulation Development and Bioavailability Evaluation of a Selfnano-emulsifying Drug Delivery System (SNEDDS) of Atorvastatin Calcium. Int J Pharm 2013; 29: 11031113.

17. Warisnoicharoen W, Lansley AB, Lawrence MJ. Nonionic oil-in-water microemulsions: the effect of oil type on phase behaviour. Int J Pharm 2000; 198: 7-27. 
Table 1: Solubility of Atorvastatin calcium in various excipients

\begin{tabular}{|c|c|c|}
\hline S.No. & Excipients & Solubility (mg/ml) \\
\hline 1. & Virgin sesame oil & $15.36 \pm 0.006$ \\
\hline 2. & Virgin coconut oil & $25.37 \pm 0.015$ \\
\hline 3. & Sunflower oil & $30.13 \pm 0.02$ \\
\hline 4. & Corn oil & $4.86 \pm 0.030$ \\
\hline 5. & Mustard oil & $10.35 \pm 0.01$ \\
\hline 6. & Rice bran oil & $12.29 \pm 0.040$ \\
\hline 7. & Olive oil & $17.62 \pm 0.010$ \\
\hline 8. & Peceol & $12.84 \pm 0.021$ \\
\hline 9. & Labrasol & $89.23 \pm 0.015$ \\
\hline 10. & Labrafil 1944CS & $1.78 \pm 0.011$ \\
\hline 11. & Labrafil 2125 & $1.62 \pm 0.012$ \\
\hline 12 & Capryol PGMC & $2.22 \pm 0.006$ \\
\hline 13. & Transcutol HP & $38.62 \pm 0.28$ \\
\hline \multicolumn{3}{|c|}{ Solvents } \\
\hline 14. & Distilled water & $0.0096 \pm 0.012$ \\
\hline $15 .$. & Methanol & $0.666 \pm 0.002$ \\
\hline 16. & pH Phosphate buffer 7.4 & $0.0095 \pm 0.013$ \\
\hline 17. & Acetonitrile & $0.0092 \pm 0.003$ \\
\hline 18. & Ethanol & $0.0089 \pm 0.014$ \\
\hline 19. & Dimethyl sulphoxide & $0.0793 \pm 0.022$ \\
\hline 20. & Dimethyl formamide & $0.0757 \pm 0.003$ \\
\hline 21. & Aqueous solution of $\mathrm{pH} 4$ & $0.02 \pm 0.005$ \\
\hline
\end{tabular}

* Values are mean $\pm S D(n=3)$

Table 2: Composition of various formulations of atorvastatin calcium

\begin{tabular}{|l|l|l|l|l|}
\hline $\begin{array}{l}\text { Formulation Code } \\
\text { (FC) }\end{array}$ & Oil (mg) & Smix $(\mathbf{m g})$ & $\begin{array}{l}\text { Particle size } \\
(\mathbf{n m})\end{array}$ & $\begin{array}{l}\text { Drug Loading } \\
(\%)\end{array}$ \\
\hline AF1 & 40 & 70 & $106.8 \pm 4.08$ & $81.8 \pm 6.63$ \\
\hline AF2 & 40 & 50 & $172 \pm 7.5$ & $83.1 \pm 4.54$ \\
\hline AF3 & 80 & 50 & $290 \pm 4.9$ & $91.5 \pm 2.78$ \\
\hline AF4* & 60 & 50 & $169.7 \pm 3.23$ & $87.2 \pm 1.23$ \\
\hline AF5 & 40 & 30 & $415 \pm 8.7$ & $70.1 \pm 2.25$ \\
\hline AF6 & 80 & 70 & $285 \pm 8.6$ & $87.6 \pm 1.65$ \\
\hline
\end{tabular}




\begin{tabular}{|l|l|l|l|l|}
\hline AF7 & 80 & 30 & $229.7 \pm 4.98$ & $89.1 \pm 4.53$ \\
\hline AF8 & 60 & 30 & $197.6 \pm 5.65$ & $75.1 \pm 2.75$ \\
\hline AF9 & 60 & 70 & $233.1 \pm 3.44$ & $86.1 \pm 4.37$ \\
\hline
\end{tabular}

Table 3: Self-emulsifying and drug precipitation of atorvastatin calcium SEDDS

\begin{tabular}{|l|l|l|l|}
\hline Formulation Code & Visibility grade & Phase separation & Precipitation \\
\hline AF1 & IV & + & ++ \\
\hline AF2 & III & + & ++ \\
\hline AF3 & IV & + & ++ \\
\hline AF4* & I & X & XX \\
\hline AF5 & II & X & XX \\
\hline AF6 & III & + & ++ \\
\hline AF7 & IV & X & ++ \\
\hline AF8 & V & + & ++ \\
\hline AF9 & III & + & ++ \\
\hline
\end{tabular}

$X$ - No phase separation, $X X$-No precipitation, +-phase separation and ++-precipitation

Table 4: Refractive index, Turbidity, Optical clarity, Polydispersity Index, Viscosity, Cloud point measurement and Emulsification time of SEDDS formulations of atorvastatin calcium

\begin{tabular}{|c|c|c|c|c|c|c|c|}
\hline FC & $\begin{array}{l}\text { Refractive } \\
\text { Index } \\
\pm \operatorname{SD}(n=3)\end{array}$ & $\begin{array}{l}\text { Turbidi } \\
\text { ty } \\
\text { (NTU) }\end{array}$ & $\begin{array}{l}\text { Absor } \\
\text { bance }\end{array}$ & $\begin{array}{l}\text { Polydispersity } \\
\text { Index } \\
\pm \mathrm{SD}(\mathrm{n}=3)\end{array}$ & $\begin{array}{l}\text { Viscosity } \\
\text { (cps) } \\
\pm \text { SD } \\
(n=3)\end{array}$ & $\begin{array}{l}\text { Cloud point } \\
\text { measureme } \\
\text { nt }\left({ }^{\circ} \mathrm{C}\right) \\
\pm \mathrm{SD}(\mathrm{n}=3)\end{array}$ & $\begin{array}{l}\text { Emulsification } \\
\text { time (sec) }\end{array}$ \\
\hline AF1 & $\begin{array}{l}1.3343 \\
\pm 0.0006\end{array}$ & 132 & 0.402 & $0.171 \pm 0.01$ & $253 \pm 2.65$ & $78 \pm 3.46$ & 132 \\
\hline AF2 & $\begin{array}{ll}1.3352 & \pm \\
0.0003 & \end{array}$ & 146 & 0.487 & $0.244 \pm 0.005$ & $\begin{array}{ll}262 \quad \pm \\
2.66\end{array}$ & $73 \pm 3.61$ & 119 \\
\hline AF3 & $\begin{array}{ll}1.3366 & \pm \\
0.0005 & \end{array}$ & 210 & 0.529 & $1.097 \pm 0.2$ & $\begin{array}{ll}264 & \pm \\
1.73 & \end{array}$ & $75 \pm 5.57$ & 121 \\
\hline AF4* & $\begin{array}{ll}1.3331 & \pm \\
0.0002 & \end{array}$ & 90 & 0.455 & $0.381 \pm 0.03$ & $\begin{array}{ll}280 & \pm \\
2.31 & \end{array}$ & $77 \pm 3.46$ & 138 \\
\hline AF5 & $\begin{array}{ll}1.3334 & \pm \\
0.0002 & \end{array}$ & 94 & 0.432 & $0.377 \pm 0.06$ & $\begin{array}{l}291 \quad \pm \\
3.51\end{array}$ & $74 \pm 3.46$ & 126 \\
\hline
\end{tabular}




\begin{tabular}{|c|c|c|c|c|c|c|c|}
\hline AF6 & $\begin{array}{ll}1.3345 & \pm \\
0.0003 & \end{array}$ & 168 & 0.517 & $0.148 \pm 0.012$ & $\begin{array}{ll}272 & \pm \\
4.58 & \\
\end{array}$ & $78 \pm 5.20$ & 112 \\
\hline AF7 & $\begin{array}{ll}1.3363 & \pm \\
0.0006 & \end{array}$ & 320 & 0.456 & $0.379 \pm 0.06$ & $\begin{array}{ll}269 & \pm \\
2.89 & \end{array}$ & $75 \pm 3.61$ & 95 \\
\hline AF8 & $\begin{array}{ll}1.3358 & \pm \\
0.0004 & \end{array}$ & 357 & 0.493 & $0.292 \pm 0.03$ & $\begin{array}{ll}254 & \pm \\
2.66 & \end{array}$ & $75 \pm 4.36$ & 82 \\
\hline AF9 & $\begin{array}{ll}1.3349 & \pm \\
0.0004 & \end{array}$ & 92 & 0.501 & $0.128 \pm 0.04$ & $\begin{array}{ll}249 & \pm \\
2.08 & \end{array}$ & $79 \pm 4.58$ & 75 \\
\hline
\end{tabular}

Table 5: Cumulative percent release of atorvastatin calcium from various formulations

\begin{tabular}{|l|l|l|l|}
\hline \multicolumn{1}{|c|}{ Time in min } & \multicolumn{1}{|c|}{ AF4 SEDDS } & \multicolumn{1}{c|}{ API } & \multicolumn{1}{c|}{ Marketed Tablet } \\
\hline 0 & 0 & 0 & 0 \\
\hline 5 & $26.21 \pm 0.74$ & $38.69 \pm 1.24$ & $33.21 \pm 2.03$ \\
\hline 10 & $39.3 \pm 0.23$ & $47.56 \pm 0.75$ & $45.23 \pm 1.12$ \\
\hline 20 & $58.36 \pm 0.45$ & $65.22 \pm 1.12$ & $60.33 \pm 2.21$ \\
\hline 30 & $72.66 \pm 0.32$ & $80.45 \pm 1.23$ & $79.54 \pm 1.64$ \\
\hline 40 & $79.5 \pm 0.18$ & $86.23 \pm 1.56$ & $85.62 \pm 0.54$ \\
\hline 50 & $86.72 \pm 0.16$ & $89.21 \pm 2.73$ & $86.74 \pm 2.21$ \\
\hline 60 & $91.3 \pm 0.55$ & $92.34 \pm 1.23$ & $90.69 \pm 1.72$ \\
\hline 75 & $94.5 \pm 0.49$ & $93.86 \pm 0.62$ & $92.66 \pm 1.54$ \\
\hline 90 & $99.75 \pm 0.31$ & $95.64 \pm 1.26$ & $93.31 \pm 1.18$ \\
\hline
\end{tabular}

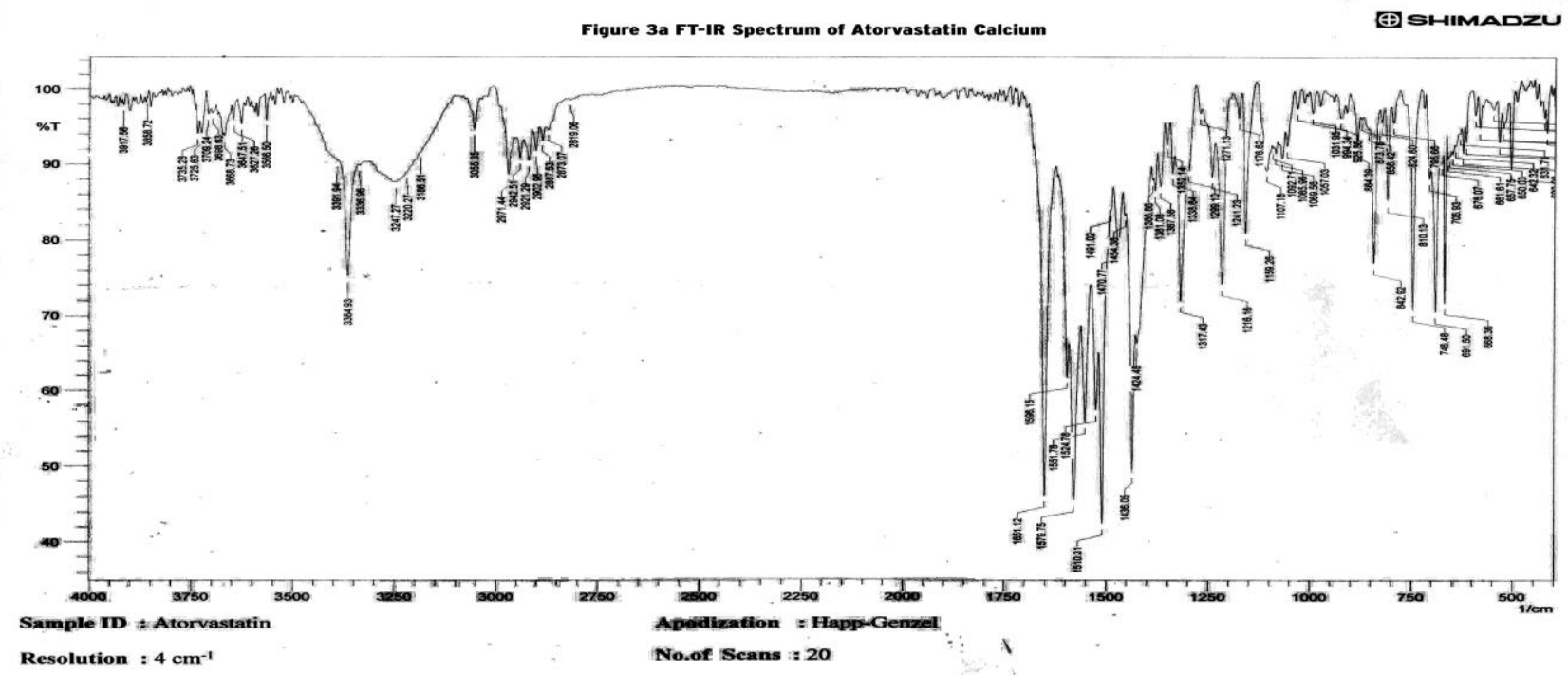

Figure 1: FT-IR spectrum of atorvastatin calcium 


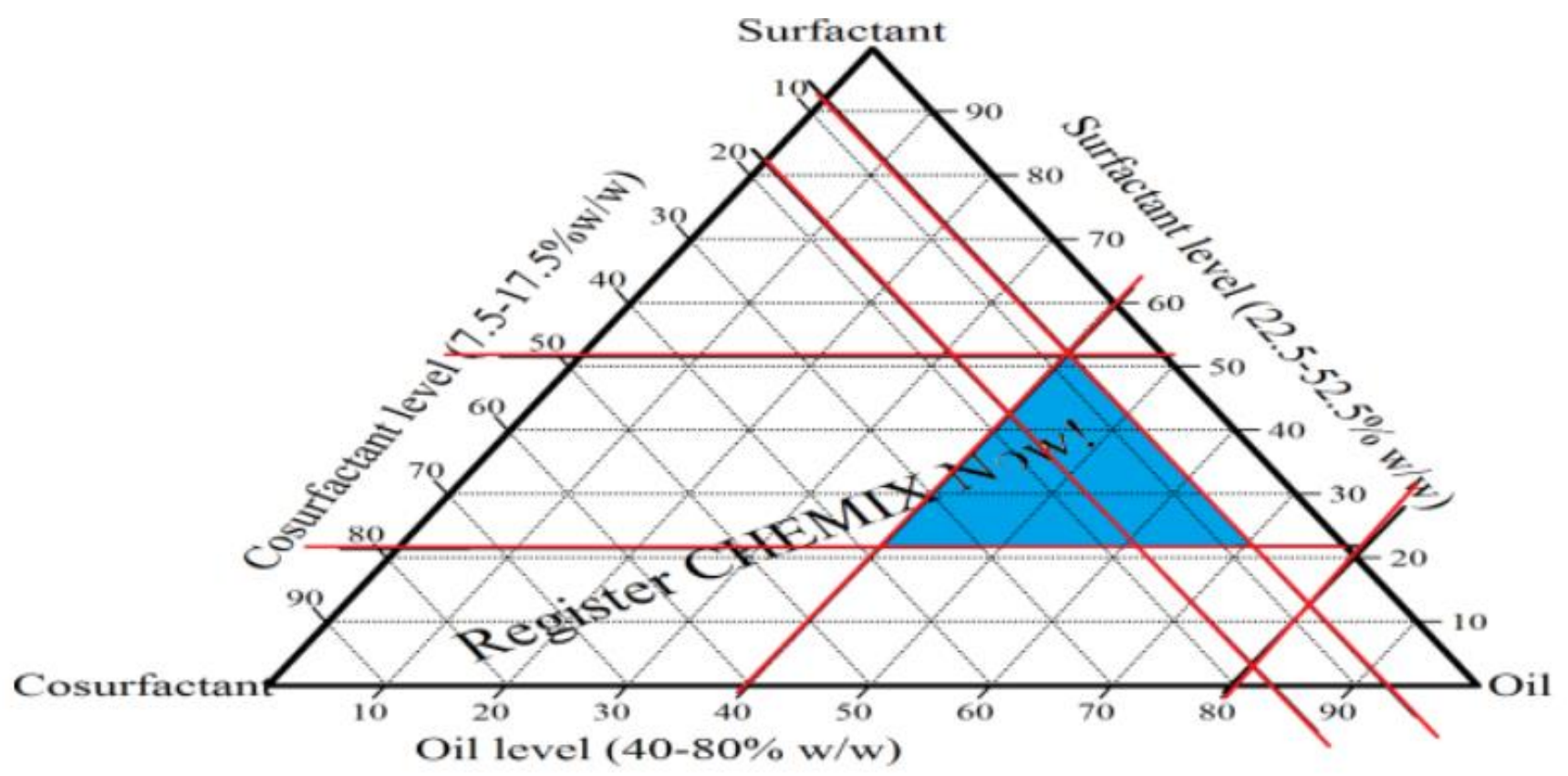

Figure 2: Ternary phase diagram of atorvastatin calcium SEDDS

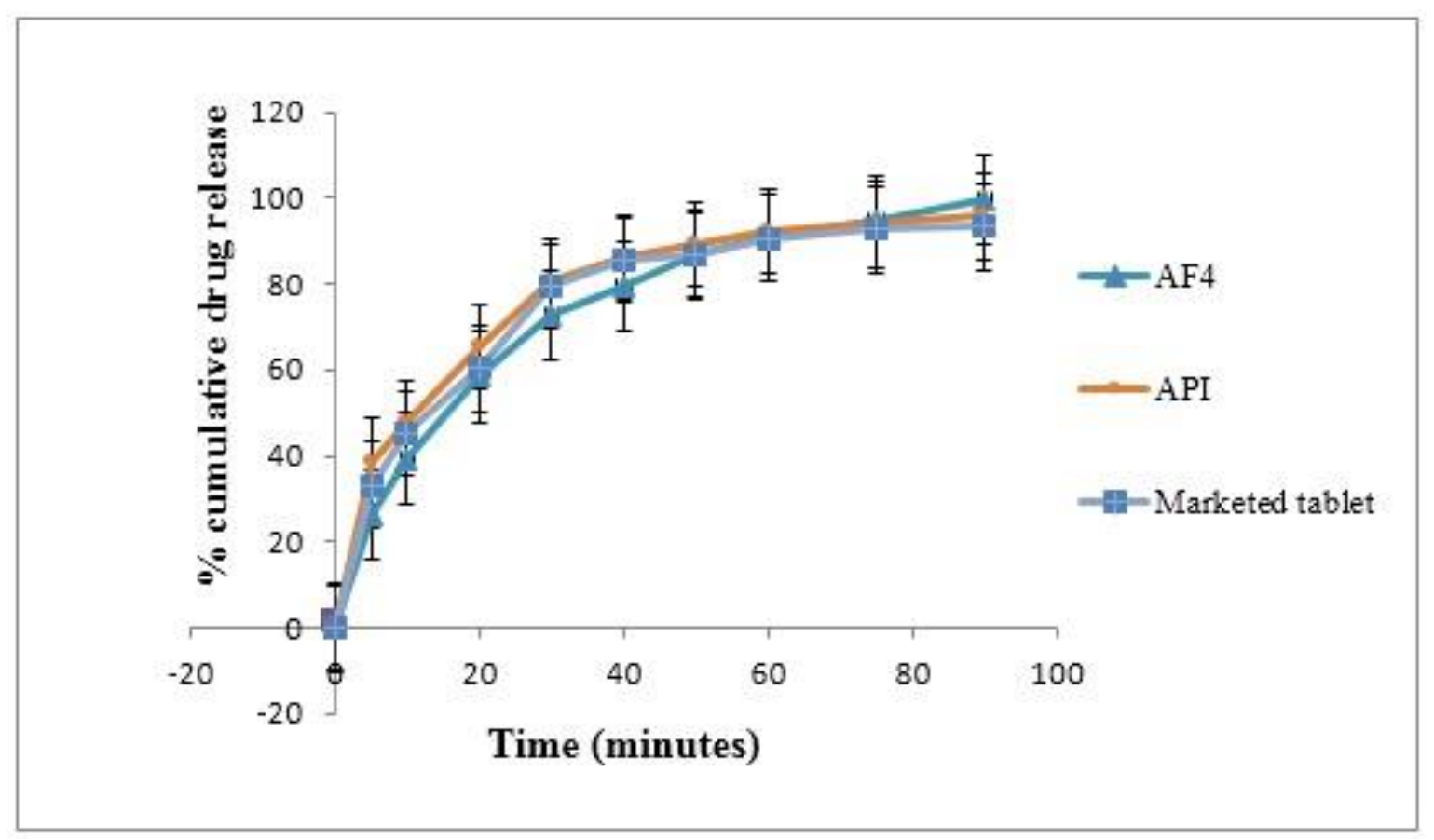

Figure 3: Dissolution comparison graph of API, marketed and optimized formulation AF4 of atorvastatin calcium SEDDS 
This manuscript was peer-reviewed

Mode of Review: Single-blinded

Editor: Dr. Isidoro Caraballo

International Journal of Pharmaceutics and Pharmacology is an open access, peer reviewed journal published by Edwiser International.

Submit your valuable manuscript at-

editor.ijpp@edwiserinternational.com

submit.manuscript@edwiserinternational.com

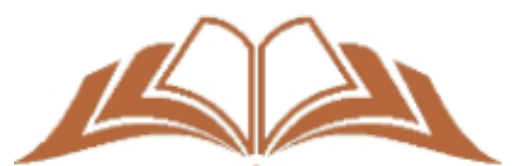

EDW $\mathrm{W}$ S E R
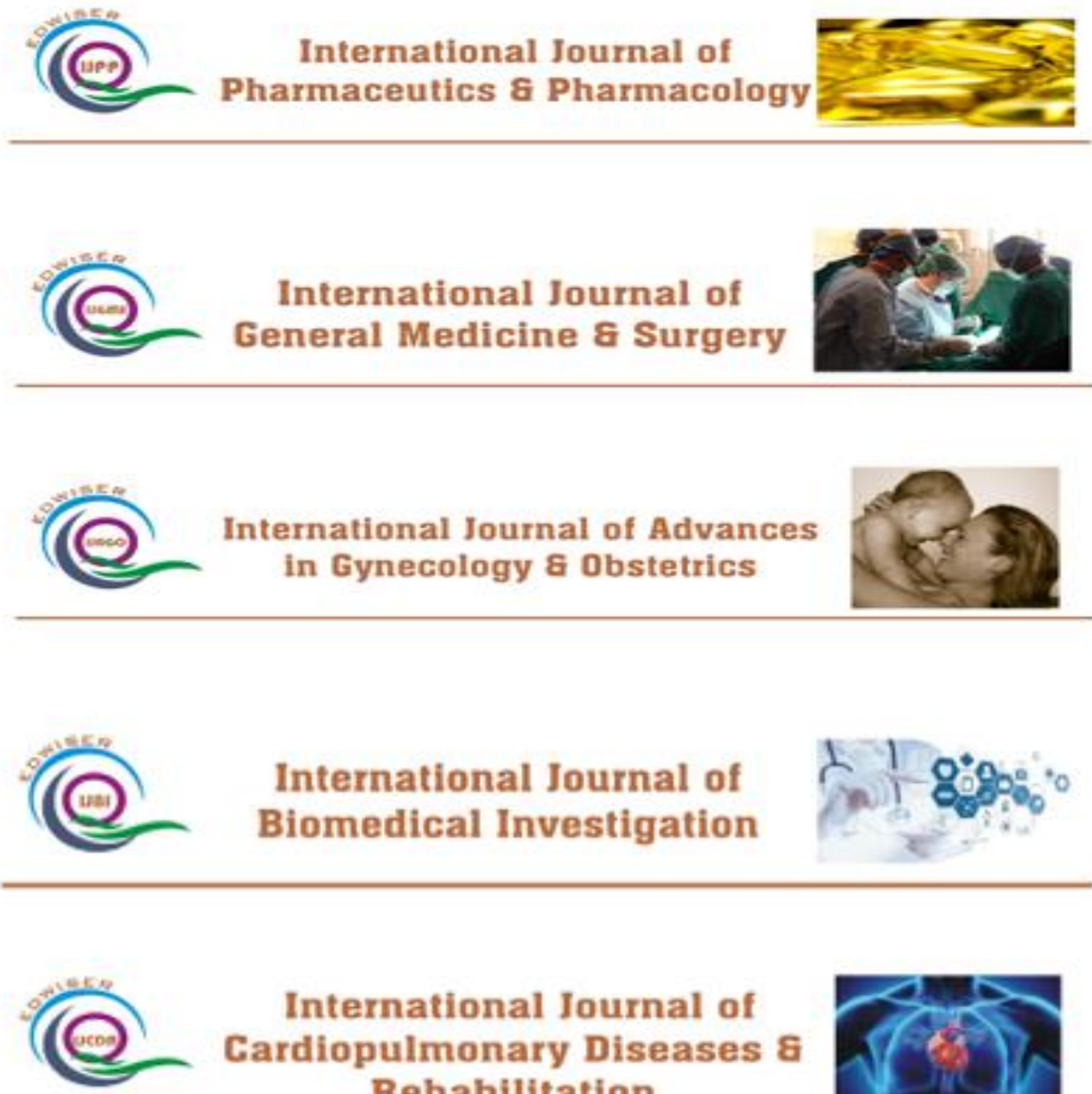

\section{International Journal of Cardiopulmonary Diseases \& Rehabilitation}

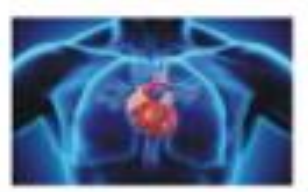

